\begin{tabular}{|c|c|c|}
\hline $\begin{array}{l}\text { OPEN ACCESS } \\
\text { Vol. } 2 \text { No. 1: 1-8 } \\
\quad \text { Tahun 2018 } \\
\text { Artikel penelitian 圆 }\end{array}$ & $\begin{array}{c}\text { Jurreal Alkwatilelestari } \\
\text { E-ISSN: 2598-8204 } \\
\text { https://ojs.umrah.ac.id/index.php/akuatiklestari } \\
\text { DoI : https://doi.org/10.31629/akuatiklestari.v2i1.919 }\end{array}$ & $\frac{1}{15}$ \\
\hline
\end{tabular}

\title{
Tingkat Kesesuaian dan Daya Dukung Wisata Pantai di Pulau Penjalin, Kabupaten Kepulauan Anambas
}

\author{
Level of Suitability and Carrying Capacity of Beach Tourism in Penjalin Island, Anambas Islands \\ Regency
}

\section{Al Mizan1 ${ }^{\bowtie}$, Febrianti Lestari $^{1}$, Susiana ${ }^{1}$}

${ }^{1}$ Manajemen Sumberdaya Perairan, Fakultas Ilmu Kelautan dan Perikanan, Universitas Maritim Raja Ali Haji, Tanjungpinang, Indonesia 29111

\section{$\square$ Info Artikel:}

Diterima: 1 September 2018

Revisi: 5 September 2018

Disetujui: 15 Oktober 2018

Dipublikasi: 20 November 2018

\section{Keyword:}

Tingkat Kesesuaian, Wisata Pantai,

Daya Dukung, Pulau Penjalin,

Kepulauan Anambas

$\triangle$ Penulis Korespondensi:

Al Mizan

Manajemen Sumberdaya Perairan,

Fakultas Ilmu Kelautan dan Perikanan,

Universitas Maritim Raja Ali Haji,

Tanjungpinang, Indonesia 29111

Email: allmiejan@gmail.com

\begin{abstract}
ABSTRAK. Penelitian ini bertujuan untuk menganalisis tingkat kesesuaian dan daya dukung wisata pantai di Pulau Penjalin, Kabupaten Kepulauan Anambas. Penentuan titik stasiun menggunakan teknik purposive sampling berdasarkan lokasi wisata pantai di Pulau Penjalin, Kabupaten Kepulauan Anambas. Untuk pengambilan data parameter ekologi dilakukan dengan metode survei. Hasil penelitian ini menunjukkan indeks kesesuaian wisata pantai di Pulau Penjalin pada stasiun 1 adalah 90,60\% dan pada stasiun 2 adalah 97,44\%, dengan tingkat kesesuaian wisata pantai pada kedua stasiun dikategorikan sangat sesuai. Daya dukung kawasan di Pulau Penjalin untuk aktivitas wisata pantai pada stasiun 1 sebanyak 478 jiwa dan dan stasiun 2 sebanyak 1.594 jiwa, dengan luas area pemanfaatan seluas $50 \mathrm{~m}^{2} /$ orang dan waktu kunjungan selama 3 jam/orang/hari.
\end{abstract}

ABSTRACT. This study aims to analyze the suitability and carrying capacity of coastal tourism on Penjalin Island, Anambas Islands Regency. Determination of the station point using a purposive sampling technique based on the location of beach tourism in Penjalin Island, Anambas Islands Regency. To collect data about ecological parameters using a survey method. The results of this study indicate the suitability index of beach tourism on Penjalin Island at station 1 is $90.60 \%$ and at station 2 is $97.44 \%$, with the suitability level of beach tourism at both stations categorized very suitable. The carrying capacity of the area on Penjalin Island for beach tourism activities at station 1 is 478 people and station 2 is 1,594 people, with an area of $50 \mathrm{~m}^{2} /$ person and visiting time of 3 hours/person/day.

\section{涌 How to cite this article:}

Mizan, A., Lestari, F.. \& Susiana. (2018). Tingkat Kesesuaian dan Daya Dukung Wisata Pantai di Pulau Penjalin, Kabupaten Kepulauan Anambas. Jurnal Akuatiklestari, 2(1): 1-8. https://doi.org/10.31629/akuatiklestari.v2i1.919

\section{PENDAHULUAN}

Kabupaten Kepulauan Anambas memiliki banyak pulau-pulau, dengan jumlah 255 pulau-pulau kecil dan hanya 26 pulau yang telah berpenghuni (DKP Kab. Kepulauan Anambas, 2018). Kondisi ini dapat dikembangkan, agar menjadikan pulau-pulau yang ada di Kepulauan Anambas menjadi daerah tujuan wisata yang dapat bersaing di Indonesia maupun di kancah Internasional. Pengembangan kawasan pantai untuk keperluan rekreasi di Indonesia akhir-akhir ini cenderung meningkat, bersamaan dengan semakin digiatkannya bidang kepariwisataan, selain itu kepariwisataan juga dapat menunjang perekonomian lokal (Satria. 2009).

Salah satu pulau-pulau kecil di KepulauanAnambas yang sudah dalam keadaan pengembangan untuk pariwisata ialah Pulau Bawah, yang memiliki daya tarik yang luar biasa. Namun bukan hanya itu, salah satu pulau yang juga memiliki keindahan lainnya ialah Pulau Penjalin. Pulau Penjalin merupakan salah satu pulau yang ada di Kecamatan Palmatak Kabupaten Kepulauan Anambas. Pulau ini memiliki daya tarik pantai yang berpasir putih dan bongkahan batu besar yang terdapat di ujung pantai. Pulau ini biasanya hanya di akses pada saat liburan-liburan tertentu saja oleh masyarakat sekitar. Pulau ini memiliki pantai yang panjang dan putih serta air laut yang sangat jernih, sehingga cocok dijadikan sebagai tempat wisata pantai.

Namun kurangnya perhatian dari pemerintah setempat baik dalam pengelolaan dan pemanfatan sehingga Pulau Penjalin yang memiliki daya tarik wisata ini terbiarkan begitu saja. Promosi daerah wisata Pulau Penjalin hanya diiklankan lewat media sosial tanpa adanya penelitian lebih lanjut. Sehingga data dan informasi tentang potensi ekologi dan daya dukung kawasan di Pulau Penjalin sangatlah penting untuk dimiliki oleh instansi-instansi terkait sehingga dapat melakukan keputasan yang lebih tepat dalam mengelola sumberdaya yang ada di Pulau Penjalin. Penelitian ini 
bertujuan untuk menganalisis tingkat kesesuaian dan daya dukung wisata pantai di Pulau Pejalin, Kabupaten Kepulauan Anambas.

\section{BAHAN DAN METODE}

\subsection{Waktu dan tempat}

Penelitian ini dilaksanakan pada bulan April sampai dengan Agustus 2018 di Pantai Pulau Penjalin, Desa Tebang, Kecamatan Palmatak, Kabupaten Kepulauan Anambas. Adapun lokasi penelitian dapat dilihat pada Gambar 1.

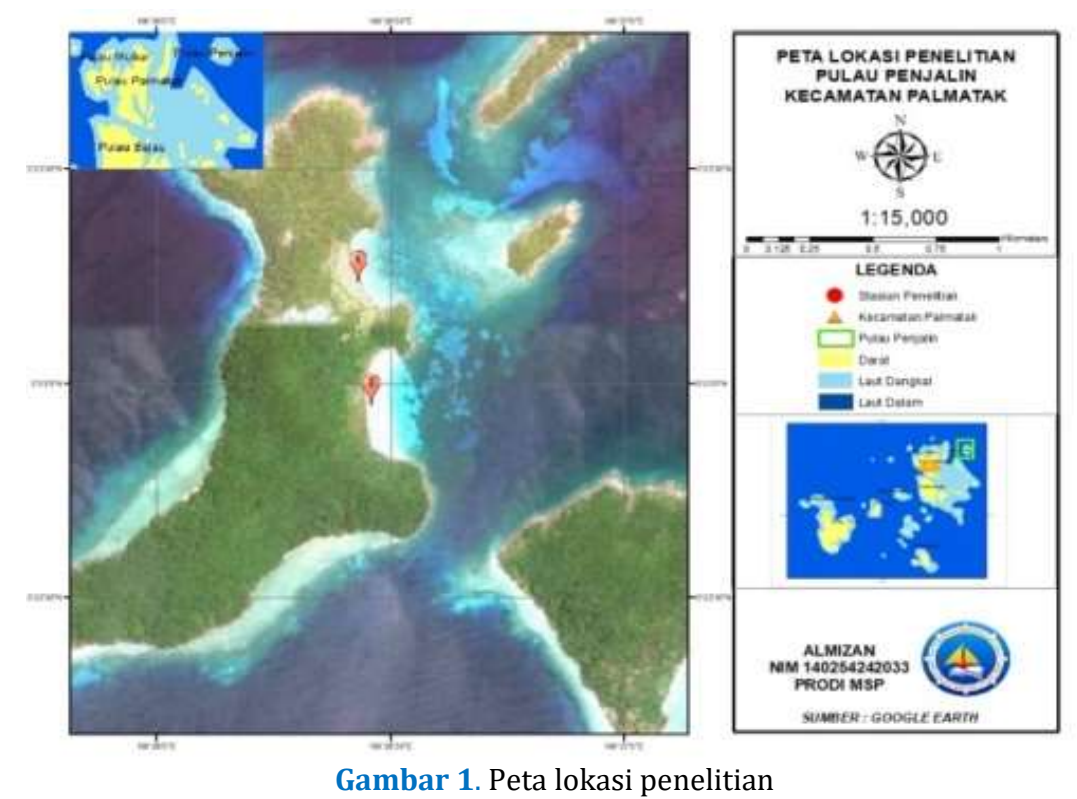

\subsection{Alat dan Bahan}

Alat-alat yang digunakan dalam penelitian ini antara lain alat tulis untuk mencatat hasil pengamatan in situ, tongkat skala untuk mengukur kedalaman perairan, kamera sebagai dokumentasi, roll meter untuk mengukur lebar pantai, tali dan botol untuk mengukur kecepatan arus, GPS (global positioning system) untuk menentukan titik koordinat, secchi disk untuk mengukur kecerahan, laptop sebagai pengolah data, kuisioner lembar wawancara, literatur lainnya sebagai data sekunder, waterpass untuk mengukur kemiringan pantai, sieve net sebagai penentuan material dasar perairan, oven untuk mengeringkan substrat, plastik sampel sebagai wadah substrat dan vegetasi, alumunium foil sebagai wadah mengeringkan substrat, timbangan analitik untuk menimbang sampel substrat, cawan petri sebagai wadah menimbang sampel susbtrat, sikat bulu untuk membersihkan sieve net, dan stopwatch untuk menghitung kecepatan arus.

Bahan-bahan yang digunakan dalam penelitian meliputi bahan yang menjadi objek penelitian di lapangan dan bahan yang digunakan dalam analisis laboratorium. Bahan yang digunakan dalam penelitian ini yaitu, substrat sebagai analisis fraksi substrat, vegetasi untuk identifikasi vegetasi penutupan lahan pantai dan alumunium foil untuk mengeringkan substart.

\subsection{Prosedur Penelitian}

Penentuan titik stasiun sampling penelitian untuk dilakukan dengan teknik purposive sampling. Pertimbangan menggunakan teknik ini karena purposive sampling adalah teknik pengambilan data dengan tujuan tertentu (Heridansyah, 2012). Dalam penelitian ini terdapat dua stasiun dimana kedua stasiun berada di bagian Barat laut Pulau Penjalin. Kedua stasiun memiliki karakteristik yang hampir sama dimana memiliki pantai yang berpasir putih dan perairan yang tenang. Pengukuran setiap parameter pada kedua stasiun dilakukan tiga kali pengulangan agar data yang didapatkan lebih akurat (Yulisa et al. 2016).

Penelitian ini dilakukan melalui beberapa tahap proses penelitian, yaitu pada tahap pertama dengan melakukan identifikasi kondisi dan potensi dari sumberdaya yang ada di kawasan tersebut melalui analisa potensi sumbedaya. Tahap kedua, melakukan analisa kesesuaian kawasan wisata untuk wisata pantai. Tahap ketiga, yaitu menganalisis daya dukung kawasan untuk wisata pantai.

\subsection{Teknik Pengumpulan Data}

Adapun parameter biofisik pantai yang diambil dalam penelitian ini adalah kedalaman perairan, tipe pantai, lebar pantai, kemiringan pantai, material dasar perairan, kecepatan arus, kecerahan perairan, biota berbahaya, vegetasi pantai dan bongkahan batu, dengan menggunakan matriks kesesuaian yang mengacu pada Yulianda (2007) dan kemudian dimodifikasi. Adapun jenis data yang dikumpulkan pada penelitian ini disajikan pada Tabel 1. 
Tabel 1. Pengumpulan Data Biofisik Pantai

\begin{tabular}{clccc} 
No & Data Biofisik Pantai & Satuan & Alat Ukur & Metode Pengukuran \\
1 & Kedalaman pantai & $\mathrm{m}$ & Tongkat skala & insitu \\
2 & Tipe pantai & & Visual & insitu \\
3 & Lebar pantai & $\mathrm{m}$ & Roll meter & insitu \\
4 & Kemiringan pantai & $\circ$ & Tongkat skala, roll meter & insitu \\
& & & dan waterpass & Laboratorium \\
5 & Material dasar perairan & & Sieve et & insitu \\
6 & Kecepatan arus & $\mathrm{m} / \mathrm{s}$ & Layangan arus & insitu \\
7 & Kecerahan & $\%$ & Secchi disk & insitu \\
8 & Biota berbahaya & & Visual & insitu \\
9 & Bongkahan batu & & Visual & \\
\hline
\end{tabular}

Sumber : Yulianda (2007) modifikasi Mizan (2018)

\subsection{Analisis Data}

Matriks kesesuaian wisata pantai mengacu pada Yulianda (2007), kemudian dimodifikasi pada parameter dan bobot. Adanya penambahan bongkahan batu karena dianggap penting dalam mendukung wisata pantai dan penambahan bobot menjadi 3 pada parameter biota berbahaya. Secara jelas matrik kesesuaian wisata pantai disajikan pada Tabel 2. Adapun kelas indeks kesesuaian wisata disajikan pada Tabel 3.

Tabel 2. Pengumpulan Data Biofisik Pantai

\begin{tabular}{|c|c|c|c|c|c|c|c|c|c|c|}
\hline \multirow{2}{*}{ No } & \multirow{2}{*}{ Parameter } & \multirow{2}{*}{ Bobot } & \multicolumn{8}{|c|}{ Kategori Kelas Kesesuaian (skor) } \\
\hline & & & S1 & Skor & $\mathbf{S 2}$ & Skor & S3 & Skor & $\mathbf{N}$ & Skor \\
\hline 1 & Kedalaman pantai (m) & 5 & $0-3$ & 3 & $>3-6$ & 2 & $>6-10$ & 1 & $>10$ & 0 \\
\hline 2 & Tipe pantai & 5 & Pasir & 3 & $\begin{array}{c}\text { Pasir } \\
\text { sedikit } \\
\text { berkerikil }\end{array}$ & 2 & Berlumpur & 1 & $\begin{array}{l}\text { Lumpur, } \\
\text { terjal }\end{array}$ & 0 \\
\hline 3 & Lebar pantai (m) & 5 & $>30$ & 3 & $<30-10$ & 2 & $<10-3$ & 1 & $<3$ & 0 \\
\hline 4 & Kemiringan pantai $\left(^{\circ}\right)$ & 3 & $<10$ & 3 & $>10-25$ & 2 & $>25-50$ & 1 & $>51$ & 0 \\
\hline 5 & Material dasar perairan & 3 & Pasir & 3 & $\begin{array}{l}\text { Karang } \\
\text { berpasir }\end{array}$ & 2 & $\begin{array}{c}\text { Pasir } \\
\text { berlumpur }\end{array}$ & 1 & Lumpur & 0 \\
\hline 6 & Kecepatan arus $(\mathrm{m} / \mathrm{s})$ & 3 & $0-0,17$ & 3 & $0,18-0,34$ & 2 & $0,35-0,51$ & 1 & $>0,51$ & 0 \\
\hline 7 & Kecerahan (\%) & 3 & $100-80$ & 3 & $<80-50$ & 2 & $<50-20$ & 1 & $<20$ & 0 \\
\hline 8 & Biota berbahaya & 3 & Tidak ada & 3 & 2 jenis & 2 & 3 jenis & 1 & $>5$ jenis & 0 \\
\hline 9 & Bongkahan batu & 1 & Banyak & 3 & Jarang & 2 & Sedikit & 1 & Tidak ada & 0 \\
\hline
\end{tabular}

Sumber : Yulianda (2007) modifikasi Mizan (2018)

Tabel 3. Pengumpulan Data Biofisik Pantai

\begin{tabular}{|c|c|c|}
\hline No & Kelas Kesesuaian & Keterangan \\
\hline 1 & $\begin{array}{l}\text { S1 (Sangat sesuai) } \\
(75-100 \%)\end{array}$ & $\begin{array}{l}\text { Kawasan ekosistem pantai yang sangat sesuai untuk dimanfaatkan sebagai kawasan wisata } \\
\text { pantai, tidak mempunyai faktor pembatas yang berat atau hanya mempunya faktor } \\
\text { pembatas yang kurang berarti terhadap kondisi kawasan dan tidak terlalu memerlukan } \\
\text { masukan untuk pengembangannya sebagai objek kawasan wisata pantai. }\end{array}$ \\
\hline 2 & $\begin{array}{l}\text { S2 (Cukup sesuai) } \\
(50-<75 \%)\end{array}$ & $\begin{array}{l}\text { Kawasan ekosistem pantai yang cukup sesuai untuk dimanfaatkan sebagai kawasan wisata } \\
\text { pantai. Faktor pembatas yang agak berat untuk suatu penggunaan kegiatan tertentu secara } \\
\text { lestari. Faktor pembatas tersebut akan mempengaruhi kepuasan dalam kegiatan wisata } \\
\text { sehingga diperlukan upaya tertentu dalam pengelolaan ekosistem pantai tersebut }\end{array}$ \\
\hline 3 & $\begin{array}{l}\text { S3 (Sesuai bersyarat) } \\
(25-<50 \%)\end{array}$ & $\begin{array}{l}\text { Kawasan ekosistem pantai yang sesuai namun bersyarat untuk dimanfaatkan sebagai } \\
\text { kawasan wisata pantai. Kategori ini memiliki faktor pembatas yang lebih banyak untuk } \\
\text { dipenuhi. Faktor pembatas tersebut akan mengurangi kepuasan sehingga untuk melakukan } \\
\text { kegiatan wisata faktor pembatas tersebut harus lebih diperhatikan sehingga ekosistem } \\
\text { dapat dipertahankan. }\end{array}$ \\
\hline 4 & $\begin{array}{l}\text { N (Tidak sesuai) } \\
(<25 \%)\end{array}$ & $\begin{array}{l}\text { Kawasan ekosistem pantai yang mengalami kerusakan yang tinggi atau tidak memiliki } \\
\text { keunggulan fisik kawasan sehingga tidak memungkinkan untuk dikembangkan sebagai } \\
\text { kawasan wisata pantai. Sangat disarankan untuk dilakukan perbaikan atau pengelolaan } \\
\text { secara berkelanjutan. }\end{array}$ \\
\hline
\end{tabular}

Sumber : Yulianda (2007) modifikasi Mizan (2018)

Analisis kesesuaian wisata dilakukan untuk mengetahui kesesuaian kawasan untuk wisata pantai perhitungan indeks kesesuaian wisata berdasarkan Yulianda (2007). Rumus yang digunakan untuk menghitung indeks kesesuaian wisata adalah sebagai berikut:

$$
I K W=\Sigma \frac{[N i]}{N \text { maks }} \times 100 \%
$$




\section{Keterangan:}

$\mathrm{IKW}=$ Indeks Kesesuaian Wisata (\%)

$\mathrm{Ni} \quad=$ Nilai parameter ke-i (Bobot $\mathrm{x}$ Skor)

Nmaks $=(\Sigma$ bobot maks $\mathrm{x}$ skor maks $)$

Analisis daya dukung kawasan mengacu rumus Yulianda (2007) sebagai berikut:

Keterangan:

$$
\mathrm{DDK}=\mathrm{K} \times \frac{\mathrm{Lp} \times \mathrm{Wt}}{\mathrm{Lt} \times \mathrm{Wp}}
$$

DDK = Daya Dukung Kawasan

$\mathrm{K} \quad$ = Potensi ekologis pengunjung

Lp $\quad=$ Luas area

$\mathrm{Lt} \quad=$ Unit area untuk kategori tertentu (wisata pantai $=50 \mathrm{~m}^{2}$ )

$\mathrm{Wt}$ = Waktu yang disediakan oleh pengelola $(6 \mathrm{jam})$

$\mathrm{Wp}=$ Waktu yang dihabiskan oleh pengunjung ( 3 jam)

\section{HASIL DAN PEMBAHASAN}

\subsection{Potensi Ekologi Pantai Pulau Penjalin}

\section{1.l. Kedalaman Pantai}

Kedalaman perairan menjadi faktor penting dalam penentuan suatu kawasan untuk dijadikan kawasan wisata pantai karena berhubungan dengan kegiatan seperti berenang oleh wisatawan (Lelloltery et al., 2016). Hasil pengukuran kedalaman dapat dilihat pada Gambar 2.

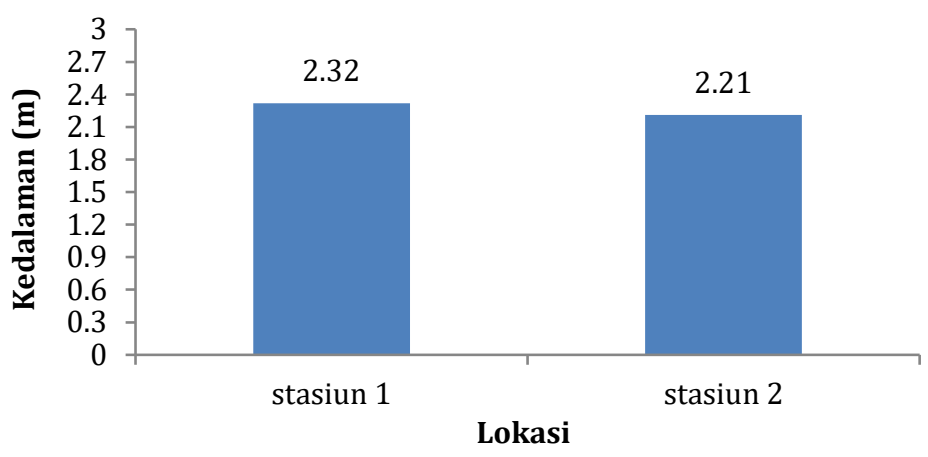

Gambar 2. Kedalaman Perairan di Pantai Pulau Penjalin

Gambar 2 dapat dilihat kedua stasiun memiliki ke dalam yang berbeda pada stasiun 1 adalah 2,32 m dan stasiun 2 adalah 2,21 m. Berdasarkan matriks kesesuaian wisata kedalam perairan yang sangat baik untuk wisata pantai adalah kurang dari 3 meter. Sehingga kedalaman perairan pada kedua stasiun terkategori SI atau sangat sesuai.

Hasil penelitian diatas dapat disimpulkan bahwa Pulau Penjalin sangat cocok dijadikan tempat rekreasi pantai dan berenang karena para pengunjung dapat melakukan aktifitas renang dengan aman. Kedalaman yang sesuai tersebut juga disebutkan dalam peneliti sebelumnya Yulisa et al. (2016), bahwa kedalaman perairan merupakan aspek yang cukup penting yang diperhitungkan dalam penentuan suatu kawasan untuk dijadikan sebagai kawasan wisata pantai khususnya mandi dan renang karena sangat berpengaruh pada aspek keselamatan pada saat berenang.

\subsubsection{Tipe Pantai}

Tipe pantai merupakan salah satu hal yang penting dalam berwisata karena pada umumnya wisatawan lokal maupun mancanegara menyukai bentuk pasir yang halus atau pantai berpasir. Kondisi pantai yang berkerikil dan berlumpur pada umumnya kurang disukai oleh para wisatawan hal ini dikarenakan kurangnya aktifitas yang bisa dilakukan.

Tipe pantai di Pulau Penjalin tergolong sebagai pantai yang berpasir putih pada kedua stasiun, baik di stasiun 1 dan stasiun 2. Sehingga tipe pantai Pulau Penjalin termasuk dalam kategori (S1) atau sangat sesuai dan mendapatkan skor 3. Pantai berpasir lebih sesuai untuk kegiatan wisata dari pada pantai berlumpur maupun berkarang (Tambunan, 2013).

\subsubsection{Lebar Pantai}

Pengukuran lebar pantai dimaksudkan untuk mengetahui seberapa besar wilayah pantai yang dapat digunakan untuk berbagai kegiatan wisata pantai. Hasil pengukuran di kedua stasiun pengamatan Pantai Pulau Penjalin menunjukkan lebar pantai tergolong cukup lebar, untuk lebih jelasnya dapat dilihat pada Tabel 4. 
Tabel 4. Lebar Pantai Pulau Penjalin

\begin{tabular}{cc} 
Stasiun & Lebar Pantai (m) \\
1 & $14,11(\mathrm{~m})$ \\
2 & $71,24(\mathrm{~m})$ \\
\hline
\end{tabular}

Stasiun 1 memiliki lebar pantai sebesar 14,1l meter dan termasuk katagori (S2) atau cukup sesuai, dan stasiun 2 memiliki lebar pantai sebesar 71,24 meter tergolong dalam katagori (S1) atau sangat sesuai. Menurut Casanah et al. (2017), lebar pantai berkaitan dengan luasan lahan yang dapat dimanfaatkan berbagai kegiatan rekreasi pantai, karena kondisi lebar pantai yang luas dapat membuat pengunjung lebih leluasa melakukan aktivitas.

\subsubsection{Kemiringan Pantai}

Kemiringan pantai merupakan salah satu parameter yang penting dalam mengetahui kesesuaian wisata pantai, karena banyak kegiatan dan aktifitas yang dilakukan dalam sehingga dapat mempengaruhi aktivitas tersebut, baik itu bermain di pantai, berfoto dan aktifitas lainnya .Hasil pengukuran kemiringan pantai yang dilakukan langsung di Pantai Pulau Penjalin. Data kemiringan pantai dapat dilihat pada Tabel 5.

Tabel 5. Kemiringan Pantai Pulau Penjalin

\begin{tabular}{cc} 
Stasiun & Kemiringan Pantai $^{\circ}$ ) \\
1 & 11,01 \\
2 & 4,49 \\
\hline
\end{tabular}

Berdasarkan Tabel 2. disimpulkan bahwa kemiringan pantai stasiun 1 dikategorikan (S2) atau cukup sesuai dan pada stasiun 2 terkategori (Sl) atau sangat sesuai. Berdasarkan matriks kesesuaian wisata yang sangat sesuai untuk kemiringan pantai adalah kurang dari 10 derajat. Menurut Subandi et al. (2018), pantai datar sampai landai sangat baik untuk kegiatan wisata renang dimana wisatawan dapat melakukan berbagai kegiatan seperti berenang, bermain pasir serta dapat bermain-main dengan ombak di tepi pantai.

\subsubsection{Material Dasar Perairan}

Material dasar dianalisis jenis sedimen dengan menggunakan sievenet dan diolah dengan menggunakan gradistat. Jenis material dasar Pantai Pulau Penjalin dapat dilihat pada Tabel 6.

Tabel 6. Material Dasar Pulau Penjalin

\begin{tabular}{ccccc} 
Stasiun & \multicolumn{3}{c}{ Persentase Fraksi (\%) } & Jenis Substrat \\
& Kerikil (Gravel) & Pasir & Lumpur & Pasir (Medium Sand) \\
1 & $0,4 \%$ & $99,6 \%$ & $0,0 \%$ & Pasir (Fine Sand) \\
\hline
\end{tabular}

Jenis substrat di Pantai Pulau Penjalin pada stasiun 1 didominasi oleh pasir sedang (Medium Sand) dan dikategorikan pasir dengan nilai rata-rata 99,6\%, stasiun 2 jenis material dasar perairan ialah pasir, dengan nilai rata-rata $100 \%$, jenis adalah pasir halus (Fine Sand). Sehingga material dasar Pantai Pulau Penjalin dikategorikan sangat sesuai (S1). Menurut Kamah et al. (2013), pantai berpasir merupakan pantai yang didominasi oleh hamparan atau daratan pasir, baik yang berupa pasir hitam, abu-abu atau putih.

\subsubsection{Kecepatan Arus}

Kecepatan arus sangat erat kaitannya dengan keamanan wisata dalam berenang dan aktivitas lainnya yang berhubungan dengan wisata pantai. Nilai kecepatan arus di Perairan Pulau Penjalin dapat dilihat pada Tabel 7.

Tabel 7. Kecepatan Arus di Perairan Pulau Penjalin

\begin{tabular}{cc} 
Stasiun & Kecepatan Arus (m/s) \\
1 & 0,10 \\
2 & 0,10 \\
\hline
\end{tabular}

Berdasarkan Tabel 4 di atas, kecepatan arus di Perairan Pulau Penjalin pada stasiun 1 sebesar 0,10 m/s dan stasiun 2 sebesar 0,10 m/s. Dari hasil tersebut dapat disimpulkan bahwa kecepatan arus di Pantai Pulau Penjalin relatif kecil dan termasuk kategori arus lambat, sehingga terkategori sangat sesuai (S1). Menurut Sari et.al (2012), penggolongan kecepatan arus terdiri 4 kategori yaitu arus lambat dengan kecepatan berkisar $0-0,17 \mathrm{~m} / \mathrm{s}$, arus sedang dengan kecepatan berkisar 0,17-0,34 m/s, arus cepat berkisar 0,34-0,50 m/s, dan arus sangat cepat yang berkisar 0,50-1 m/s. Hasil penelitian ini juga dibandingkan dengan penelitian Pasaribu et al. (2017), dimana kecepatan arus di Pantai Binasi berkisar antara $0,32 \mathrm{~m} / \mathrm{s}$ sampai $0,43 \mathrm{~m} / \mathrm{s}$ dan layak dijadikan sebagai tempat wisata dan termasuk dalam kategori arus sedang. 


\subsubsection{Kecerahan Perairan}

Kecerahan perairan dalam kaitannya dengan kegiatan wisata pantai sangat berperan dalam hal kenyamanan para wisatawan pada saat berenang. Pengukuran kecerahan dilakukan dengan menggunakan secchi disk yang diikat dengan tali kemudian diturunkan perlahan-lahan ke dalam perairan. Kecerahan Perairan Pulau Penjalin dapat dilihat pada Gambar 3.

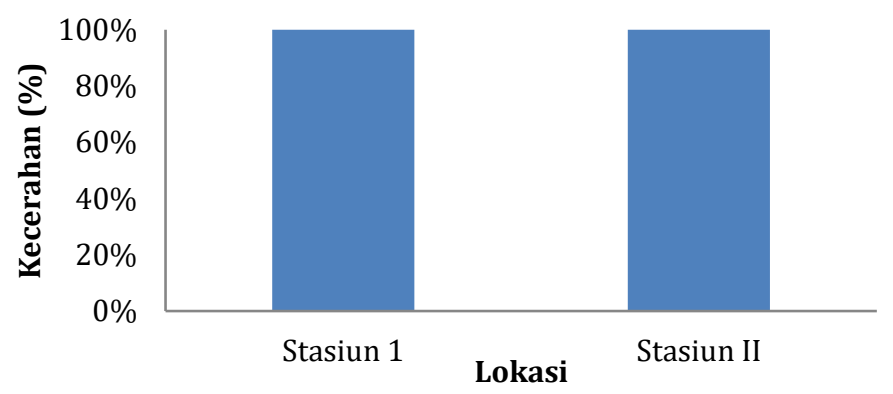

Gambar 3. Kecerahan Perairan Pulau Penjalin

Berdasarkan hasil pengukuran kecerahan di Perairan Pantai Pulau Penjalin yaitu $100 \%$ untuk kedua stasiun, artinya dasar perairan masih kelihatan dengan jelas dari permukaan air. Sehingga kecerahan perairan dikategorikan sangat sesuai (Sl) untuk wisata pantai. Penelitian ini juga sesuai dengan Cahyadinata (2009) yang melakukan penelitian di Pantai Kana Pulau Enggano, dasar perairan masih tampak dengan pengamatan visual. Sama halnya kondisi dasar perairan yang ada di Pulau Penjalin masih bisa diamati secara visual.

\subsubsection{Biota Berbahaya}

Berdasarkan pengamatan langsung di lapangan dengan melakukan snorkeling di dua stasiun yang telah ditentukan, tidak terdapat biota berbahaya di Perairan Pulau Penjalin dan dapat disimpulkan bahwa Pantai Pulau Penjalin termasuk kategori (Sl) atau sangat sesuai untuk kawasan wisata pantai.

Pengamatan biota berbahaya dilakukan dengan secara langsung di lokasi penelitian dan diamati dengan metode LIT (Line Intercept Transect) dengan cara snorkeling di sekitar 2,5 m ke kanan 2,5 m ke kiri dan kearah laut sepanjang $50 \mathrm{~m}$ vertikal (Kasnir, 2011). Pengamatan biota berbahaya dilakukan sebanyak 3 kali pengulangan.

\subsubsection{Bongkahan Batu}

Bongkahan batu dinilai berdasarkan hasil wawancara dengan responden terhadap keberadaan batu tersebut. Hasil pengamatan ke para pengunjung secara keseluruhan pengunjung menyebutkan, bahwa batu yang ada di Pulau Penjalin merupakan salah satu hal yang menarik yang jarang dijumpai di pulau-pulau lain, sehingga respon para pengunjung $100 \%$ sangat senang dengan keberadaan batu tersebut.

Salah satu hal yang mendasari keindahan Pulau Penjalin ialah dengan keberadaan bongkahan batu disetiap ujung pantainya. Menurut Salleh et al. (2012), hampir semua wisatawan lokal maupun mancanegara sangat menyetujui bahwa faktor karateristik alam adalah faktor yang mempengaruhi kepuasan wisatawan terhadap suatu kawasan wisata.

\subsection{Indeks Kesesuaian Wisata Pantai di Pulau Penjalin}

Dalam suatu kawasan wisata memerlukan kesesuaian sumberdaya dan lingkungan pesisir, kesesuaian tersebut di tujukan untuk mendapatkan karateristik sumberdaya wisata guna menentukan kegiatan wisata apa yang akan dikembangkan di kawasan pesisir tersebut (Yulianda et al., 2010). Penentuan nilai IKW didasari oleh observasi lapangan dan pengukuran yang dilakukan di dua Pantai Pulau Penjalin. Hasil analisis indeks kesesuaian wisata pantai di Pulau Penjalin Kabupaten Kepulauan Anambas pada stasiun 1 dan stasiun 2 dapat dilihat pada Tabel 8 dan 9.

Tabel 8. Indeks Kesesuaian Wisata Pantai di Stasiun 1

\begin{tabular}{clccc}
\hline No & \multicolumn{1}{c}{ Parameter } & Bobot & Skor & Hasil \\
\hline 1 & Kedalaman & 5 & 3 & 15 \\
2 & Tipe pantai & 5 & 3 & 15 \\
3 & Lebar pantai & 5 & 2 & 10 \\
4 & Kemiringan & 3 & 3 & 9 \\
5 & Material perairan & 3 & 3 & 9 \\
6 & Arus & 3 & 3 & 9 \\
7 & Kecerahan & 3 & 3 & 9 \\
8 & Biota berbahaya & 3 & 3 & 9 \\
9 & Bongkahan batu & 1 & 3 & $\mathbf{8 8}$ \\
Jumlah & & & & $\mathbf{9 4 , 6 2}$ \\
Nilai (\%) & & & & \\
\hline
\end{tabular}


Tabel 9. Indeks Kesesuaian Wisata Pantai di Stasiun 2

\begin{tabular}{clccc} 
No & \multicolumn{1}{c}{ Parameter } & Bobot & Skor & Hasil \\
1 & Kedalaman & 5 & 3 & 15 \\
2 & Tipe pantai & 5 & 3 & 15 \\
3 & Lebar pantai & 5 & 3 & 15 \\
4 & Kemiringan & 3 & 3 & 9 \\
5 & Material perairan & 3 & 3 & 9 \\
6 & Arus & 3 & 3 & 9 \\
7 & Kecerahan & 3 & 3 & 9 \\
8 & Biota berbahaya & 3 & 3 & 9 \\
9 & Bongkahan batu & 1 & 3 & 3 \\
Jumlah & & & & $\mathbf{9 3}$ \\
Nilai (\%) & & & & $\mathbf{1 0 0}$ \\
\hline
\end{tabular}

Berdasarkan hasil analsis indeks kesesuaian wisata pantai di Pulau Penjalin dapat disimpulkan bahwa kedua stasiun pengamatan dikatergorikan sangat sesuai untuk kegiatan wisata pantai. Hal ini didasarkan pada kedua stasiun memiliki kelas indeks kesesuaian yang sangat baik dimana pada stasiun 1 sebesar 94,62\% dan stasiun 2 sebesar 100\%. Salah satu faktor yang lebih unggul pada stasiun 2 ialah memiliki lebar pantai yang sangat sesuai atau (SI) yaitu sebesar 71,24 meter, sedangkan pada stasiun 2 hanya memiliki nilai lebar pantai sebesar 14,1l meter dan terkategori cukup sesuai (S2).

\subsection{Daya Dukung Kawasan Wisata Pantai di Pulau Penjalin}

Dengan adanya pembatasan jumlah maksimum pengunjung yang didasari oleh daya dukung kawasan, diharapkan sumberdaya alam dan lingkungan di kawasan tersebut dapat terhindar dari dampak negatif yang ditimbulkan dari kegiatan wisata di kawasan tersebut. Pulau Penjalin memiliki luas pantai $\pm 1,159$ ha atau $11.590 \mathrm{~m}^{2}$ pada stasiun 1 dan 3,986 ha atau $39.860 \mathrm{~m}^{2}$ pada stasiun 2. Hasil perhitungan daya dukung kawasan Pulau Penjalin disajikan pada Tabel 10 .

Tabel 10. Daya Dukung Kawasan Wisata Pantai di Pulau Penjalin

\begin{tabular}{cclcc} 
Stasiun & No & \multicolumn{1}{c}{ Variabel } & Satuan & Nilai \\
\hline 1 & 1 & Pengunjung (K) & Jiwa & 1 \\
& 2 & Luas area pantai (Lp) & $\mathrm{m}^{2}$ & 11.950 \\
& 3 & Unit Area (Lt) & $\mathrm{m}^{2}$ & 50 \\
& 4 & Waktu Kunjungan (Wp) & Jam/orang & 3 \\
& 5 & Waktu Tersedia (Wt) & Jam & 6 \\
2 & Daya Dukung Kawasan (DDK) & Jiwa & $\mathbf{4 7 8}$ \\
& 1 & Pengunjung (K) & Jiwa & 1 \\
& 2 & Luas area pantai (Lp) & $\mathrm{m}^{2}$ & 39.860 \\
& 3 & Unit Area (Lt) & $\mathrm{m}^{2}$ & 50 \\
& 4 & Waktu Kunjungan (Wp) & Jam/orang & 3 \\
& 5 & Waktu Tersedia (Wt) & Jam & 6 \\
& \multicolumn{2}{c}{ Daya Dukung Kawasan (DDK) } & Jiwa & $\mathbf{1 . 5 9 4}$ \\
\hline
\end{tabular}

Hasil perhitungan daya dukung kawasan untuk wisata di Pulau Penjalin Kabupaten Kepulauan Anambas untuk aktivitas wisata pantai pada stasiun 1 sebanyak 478 jiwa dan dan stasiun 2 sebanyak 1.594 jiwa, dengan luas area pemanfaatan seluas $50 \mathrm{~m} 2$ /orang dan waktu kunjungan selama 3 jam/orang/hari.

\section{SIMPULAN}

Tingkat kesesuaian wisata pantai di Pulau Penjalin pada kedua stasiun dikategorikan sangat sesuai. Daya dukung kawasan pada stasiun 1 sebesar 487 jiwa dalam satu hari dengan luas, sekitar $11.590 \mathrm{~m}^{2}$ dan pada stasiun 2 memiliki luas sekitar $39.860 \mathrm{~m}^{2}$ dengan daya dukung kawasan sebanyak 1.954 jiwa dalam satu hari.

\section{UCAPAN TERIMA KASIH}

Penulis mengucapkan terima kasih kepada pihak-pihak yang telah membantu proses penelitian ini, diantaraya Kepala Desa Tebang, Badan Kesbangpol, Dinas Pariwisata, serta Dinas Kelautan dan Perikanan Kabupaten Kepulauan Anambas. 


\section{REFERENSI}

Cahyadinata I. (2009). Kesesuaian Pengembangan Kawasan Pesisir Pulau Enggano Untuk Pariwisata Dan Perikanan Tangkap. Jurnal AGRISEP, 9(2): 168-182.

Chasanah, I., Purnomo, P.W., \& Hearuddin. (2017). Analisis Kesesuaian Wisata Pantai Jodo Desa Sidoarjo Kecamatan Gringsing Kabupaten Batang. Jurnal Pengelolaan Sumberdaya Alam Dan Lingkungan, 7(3): 235-243.

Heridiansyah, J. (2012). Pengaruh Advertising Terhadap Pembentukan Brand awareness Serta Dampaknya Pada Pembelian Produk Kecap Pedas ABC. Jurnal STIE Senggarang, 4(2): 53-73.

Kamah, M.H., Sahami, F.M., \& Hamzah, S.N. (2013). Kesesuaian Wisata Pantai Berpasir Pulau Saronde Kecamatan Pondo Kepulauan Kabupaten Gorontalo Utara. Jurnal Ilmu-Ilmu Pertanian, 1(1): 1-15.

Kasnir, M. (2011). Analisis Aspek Ekologi Penatakelolaan Minawisata Bahari di Kepulauan Spermonde Kabupaten Pangkep Sulawesi Selatan. Jurnal Ilmu Kelautan, 16(2): 61-69.

Lelloterry, H., Pujiatmoko, S., Fandelli, C., \& Baiquni, M.( 2016). Pengembangan Ekowisata Berbasis Kesesuaian Dan Daya Dukung Kawasan Pantai (Studi Kasus Pulau Marsegu Kabupaten Seram Bagian Barat. Jurnal Budidaya Pertanian, 12(1): 25-33.

Pasaribu, H.M., Patama, P., \& Usman, S. (2017). Analisis Kesesuaian dan Daya Dukung Wisata Pantai Binasi Kecamatan Sorkam Barat Kabupaten Tapanuli Tengah. Jurnal Aquacoastmarine, 5(4): 1-15.

Salleh, N.H.M., Othman, R., Sarmidi. T., Jaafar, A.H., \& Norghani, B.M.N. (2012). Tourist Satisfaction of the Enviromental Service Quality for Tioman Island Marine Park. Indian Journal of Geo-Marine Sciences, 41(2): 173-179.

Satria, D. (2009). Strategi Pengembangan Ekowisata Berbasisi Ekonomi Lokal Dalam Rangka Pengentasan Kemiskinan di Wilayah Kabupaten Malang. Jurnal of Indonesian Applied Economics, 3(1): 37-47.

Subandi, I.K., Dirgayusa, I.G.N.P., \& Asy-syakur, A.R. (2018). Indeks Kesesuaian Wisata di Pantai Pasir Putih Kabupaten Karangasem. Journal of Marine and Aquatic Sciences, 4(1): 47-57.

Tambunan, J.M.S., Anggoro, H., \& Purnaweni. (2013). Kajian Kualitas Lingkungan dan Kesesuaian Wisata Pantai Tanjung Pesona Kabupaten Bangka. Prosiding Seminar Nasional Pengelolaan Sumberdaya Alam dan Lingkungan 2013. 356-362.

Yulianda, F. (2007). Ekowisata Bahari Sebagai Alternatif Pemanfaatan Sumberdaya Pesisir Berbasis Konsevasi. Makalah seminar Sains Pada Dapertemen Manajemen Sumberdaya Perairan. Fakultas Perikanan Dan Ilmu Kelautan. Insitut Pertanian Bogor (IPB). Bogor.

Yulianda, F., Fachrudin, A., Ambrosius, A.H., Sri, H., \& Kusharjani, H.S.K. (2010). Pengelolaan Pesisir dan Laut Secara Terpadu. Pusdiklat Kehutanan-Secem- Koica. Bogor.

Yulisa, N.E., Johan, Y., \& Hartono, D. (2016). Analisis Kesesuaian Dan Daya Dukung Ekowisata Pantai Kategori Rekreasi Pantai Laguna Desa Merpas Kabupaten Kaur. Jurnal Enggano, 1(1). 97-111. 